\title{
Pulmonary histoplasmosis post renal transplantation in a patient at de general hospital ISSSTE at the City of Chihuahua: Case report and Literature review
}

\section{Histoplasmosis Pulmonar Post Trasplante Renal en Paciente del Hospital General ISSSTE de la Ciudad de Chihuahua: Reporte de Caso y Revisión de la Literatura}

\author{
David A. Romero-Pérez ${ }^{1 *}$, Alan Torres-Macías², and David Hernández-Ríos ${ }^{3}$ \\ ${ }^{1}$ Surgery Service; ${ }^{2}$ Internal Medicine Service; ${ }^{3}$ Cardiothoracic Surgery Department, Surgery Service. Hospital General Presidente Lázaro Cárdenas \\ Instituto de Seguridad Social y de Servicio de los Trabadores del Estado (ISSSTE), Chihuahua, Chihuahua, Mexico
}

\begin{abstract}
Pulmonary histoplasmosis today has become an increasingly frequent pathology, due to advances in therapy and control of diseases such as acquired immune deficiency syndrome, transplant associated immunosuppression therapies, as well as other conditions that confer some degree of immunocompromise in the population. A case from Chihuahua, Chihuahua has been presented, as well as a review of the existing literature, with the aim of expanding and providing information on the subject. A female patient with a history of kidney transplantation and immunosuppression therapy who presents with acute respiratory symptoms with atypical characteristics; severe acute respiratory syndrome coronavirus-2 had ruled out as the first etiological agent instance due to the present health contingency. After the failure of therapy against fungal and viral agents, it was decided to take an open thoracotomy biopsy, which was found to be Histoplasma capsulatum as the causative agent. Management started based on liposomal Amphotericin B with poor response to it. In our community, there are few reports of histoplasmosis cases, this due to the climatic and environmental characteristics; this case's analysis of severe pulmonary histoplasmosis will serve as a basis for the future research.
\end{abstract}

Key words: Pulmonary histoplasmosis. Post kidney transplantation. Immunosuppression. Histoplasma capsulatum.

\section{Resumen}

La Histoplasmosis pulmonar hoy en día se ha convertido en una patología cada vez más frecuente, esto por los avances en terapia y control de padecimientos como el Síndrome de Inmunodeficiencia Adquirida, Terapias de Inmunosupresión Asociada a Trasplantes, así como estados que confieren algún grado de inmunocompromiso a la población; es por esa razón que se presenta un caso de la Ciudad de Chihuahua, así como revisión de la literatura existente, con el objetivo de ampliar la información con respecto al tema. Se trata de paciente femenino con antecedente de trasplante renal y terapia de inmunosupresión, que cursa con cuadro respiratorio agudo de características atípicas, se descarta al SARS COV-2 como agente etiológico como primera instancia por contingencia sanitaria actual; posterior al fracaso de terapia contra agentes

Correspondence:

*David A. Romero Pérez

E-mail: romero.perez_ad@ @otmail.com
Disponible en internet: 17-12-2021 Rev Hosp Jua Mex. 2021;88(4):209-214

www.revistahospitaljuarez.com 1405-9622/( 2021 Sociedad Médico-Quirúrgica del Hospital Juárez de México, A.C. Publicado por Permanyer. Este es un artículo open access bajo la licencia CC BY-NC-ND (http://creativecommons.org/licenses/by-nc-nd/4.0/). 
fúngicos y virales se decide toma de biopsia mediante toracotomía a cielo abierto, encontrado como agente causal a Histoplasma capsulatum, se inicia manejo en base a Anfotericina $B$ con pobre respuesta al mismo. En nuestra comunidad se tienen pocos reportes de casos de Histoplasmosis, esto debido a las características climáticas y ambientales, el presente análisis de caso de Histoplasmosis Pulmonar severa servirá como base para futuras investigaciones.

Palabras clave: Histoplasmosis Pulmonar. Post trasplante renal. Inmunosupresión. Histoplasma capsulatum.

\section{Introduction}

In recent years, an increase in the frequency of fungal infections has been observed, this especially after advances in immunosuppressive therapies, increased incidence and chronicity of acquired human immunodeficiency syndrome, and organ transplants. Invasive fungal infections are a significant and sometimes fatal problem in post-transplant patients.

In a study by Abbott et al. (2001) regarding hospitalizations for fungal infections after kidney transplantation (N: 33,420), it was found that fungal infections were more frequently associated with diagnoses of esophagitis $(68.23 \%)$, pneumonia $(57.9 \%)$, meningitis (23.7\%), and urinary tract infections (29.1\%). Likewise, it has been observed that the majority of fungal infections had occurred 6 months after transplantation (66\%) and only $22 \% 2$ months after transplantation.

The diagnosis of an invasive mycosis is based on three elements: the clinical examination, the image, and the confirmation (test of the causative agent). In addition to the history of immunodeficiencies, relevant clinical risk factors include:

- Prolonged deep granulocytopenia (>10 days) $(<0.55$ $\times$ 109/L)

- Allogeneic stem cell transplantation

- Drug-induced immunosuppression

- Treatment with prednisone (the equivalent of at least $0.3 \mathrm{mg} / \mathrm{kg} /$ day for a minimum of 3 weeks) $)^{2}$.

This list is not complete because it excludes those patients who are in an important but less defined risk group, such as those patients who are in intensive care units, patients with structural pulmonary disease and patients with influenza.

Histoplasmosis is a mycosis caused by the fungus Histoplasma capsulatum; thermal fungus, with filamentous or mycelial growth in its saprophytic state, and with yeast-like or spherular growth at $37^{\circ} \mathrm{C}$ when parasitizing humans.

$H$. capsulatum infection usually occurs by inhalation of bioaerosols or dust with microconidia, the infecting elements are the microaleuriospores that reach the pulmonary alveolus; the reservoir of these infective elements is generally found in soils rich in nitrogen, soils contaminated with guano or bird and bat droppings. The geographical distribution of this fungus is found in tropical, subtropical, and temperate zones, mainly in America $^{3}$.

The intensity of the disease and the clinical form depends on the number of microconidia inhaled in the initial inoculum, as well as the integrity of the host's immune response system. histoplasmosis produces from mild and asymptomatic respiratory infections to severe clinical forms with progressive respiratory deterioration as well as massive infections. This pathology covers a wide spectrum of conditions from acute pulmonary histoplasmosis, chronic pulmonary histoplasmosis which can become a progressive disseminated histoplasmosis ${ }^{4}$.

As mentioned above, the clinical manifestations vary according to the immune status of the host as well as the infectious dose. In most cases, histoplasmosis presents with various lung symptoms, often as a subacute lung infection 3-21 days after exposure. Symptoms are usually mild, including fever, chills, headache, myalgia, anorexia, cough, and chest pain may appear in the most exposed people.

\section{Histoplasmosis diagnosis}

The present methods for the diagnosis of systemic fungal infections include imaging procedures, endoscopic methods and biopsies, microscopic and culture techniques, serological tests based on antibodies and antigens, and the detection of fungal deoxyribonucleic acid in blood or bronchoalveolar lavage fluid (through the polymerase chain reaction) ${ }^{5}$.

The gold standard for the accurate diagnosis of histoplasmosis is based on the direct visualization of $H$. capsulatum in tissues or body fluids. $H$. capsulatum takes 4-6 weeks to be detectable. The characteristic histopathological feature of histoplasmosis is the presence of caseating or non-caseating granulomas and by means of specialized staining techniques such as periodic acid schiff, giemsa, or silver methenamine, the characteristic intracellular ovoid structures are discovered. Non-invasive methods such as antigen and antibody tests are available; however, the antibody test 
against the microorganism is usually negative in immunocompromised patients ${ }^{6}$.

The most common radiographic findings in the acute and subacute forms are unilateral or bilateral pulmonary nodules and/or bilateral diffuse patchy opacities, generally associated with prominent hilar and mediastinal lymphadenopathy. Micronodules with a random pattern of dissemination (miliary pattern) in chest tomography constitute a common presentation in various pulmonary mycoses, being described more frequently in histoplasmosis. Other tomographic patterns that can be found in patients with pulmonary histoplasmosis and other pulmonary fungal infections are ground glass opacities, predominantly peripheral nodules (with or without halo sign), consolidations, and cavitation?

The case of a female patient after kidney transplantation is presented, which shows a respiratory condition with atypical characteristics.

\section{Case report}

A 30-year-old female patient who had the following important antecedents: originally came from Tulancingo, Hidalgo, residing for 4 months in Nicolás Bravo, Madera, Chihuahua. Denies drug addiction, denies exposure to biomass combustion products. As important pathological antecedents, renal hypoplasia diagnosed at 11 years of age, chronic kidney disease diagnosed at 21 years of age after pregnancy as a trigger, with initiation of renal replacement therapy by hemodialysis at 26 years; living donor kidney transplant at 28 years of age. The patient was in drug immunosuppression for 2 years after kidney transplantation with tacrolimus $3 \mathrm{mg}$ every $24 \mathrm{~h}$, Mycophenolate Mofetil $1 \mathrm{~g}$ every $12 \mathrm{~h}$, and Prednisone $5 \mathrm{mg}$ every $24 \mathrm{~h}$.

Patient who started her condition 20 days before admission with quantified fever peaks of up to $40^{\circ}$, with dyspnea of small efforts, myalgias, arthralgias, and attack on the general state without other accompanying symptoms.

Patient begun antibiotic management without a favorable response to it; the reason why she went to the Medical Unit, where, due to respiratory symptoms suggestive of coronavirus infection, a diagnostic protocol for COVID-19 was initiated, with negative results for both the serological test and polymerase chain reaction (PCR), so she was sent to the General Hospital ISSSTE Chihuahua for diagnosis and therapeutic complementation.

On admission, patient with persistent dyspnea and fever; on physical examination with evidence of respiratory distress, need for supplemental oxygen supply,

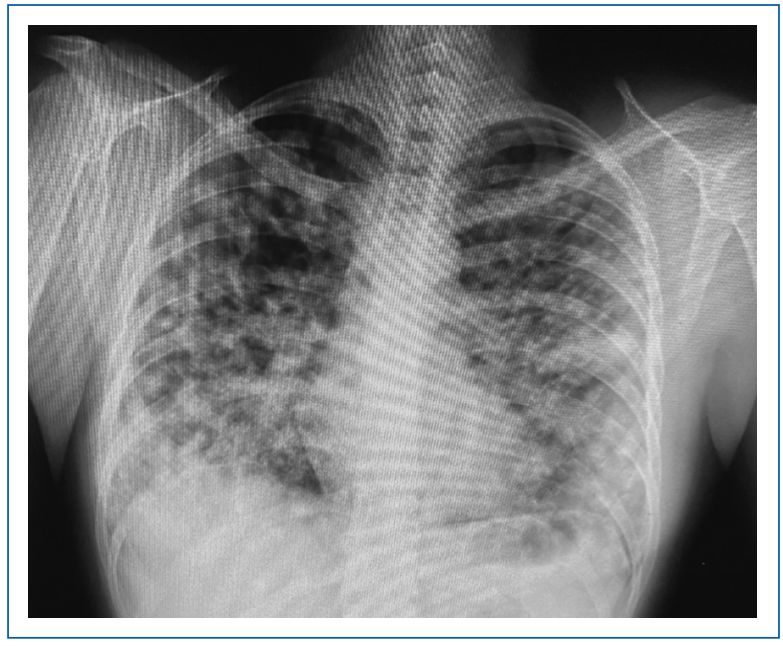

Figure 1. Chest X-ray: heterogeneous pulmonary parenchyma due to opacities of nodular morphology.

pallor of integuments as well as acrocyanosis; chest with decreased bilateral vesicular murmur with presence of bilateral diffuse rales; entrance laboratory tests: Hemoglobin 11; Hematocrit 33.3; VCM 82.6; HCM 32.3; Leukocytes 3.92; Neutrophils 3.2; Lymphocytes 0.57; Urea 128; Serum Creatinine 2.4; Sodium 140; Potassium 5.0; Chlorine 108; and PCR 170.4.

Chest X-rays with data of completely heterogeneous lung parenchyma at the expense of multiple opacities of nodular morphology, as well as opacities that suggest alveolar occupation, both lungs are well expanded, the pleural contours are clear and well-defined (Fig. 1).

Chest computed tomography (CT) reported pulmonary fields that shown an increase in the interstitial weft bilaterally with a linear pattern, bilateral hilar congestion, and bilaterally "cobblestone" pattern in multiple segments. Mediastinum with an increase in the number of nodes to be considered reactive inflammatory phenomenon (Fig. 2).

Joint management of internal medicine was started for severe pneumonic symptoms with atypical characteristics with Ganciclovir and Voriconazole, as well as a protocol to rule out renal graft rejection.

Based on the poor evolution of the patient, little response to the initial management, and the results of negative cultures, a new chest CT scan was taken and evaluation by cardiothoracic surgery to take a lung biopsy by thoracotomy was requested. During the surgery 3 weeks after her admission, the following surgical findings were observed: open biopsy of the right lower lobe, found $100 \mathrm{cc}$ sallow pleural effusion and macroscopic characteristics of lung tissue with whitish patches 


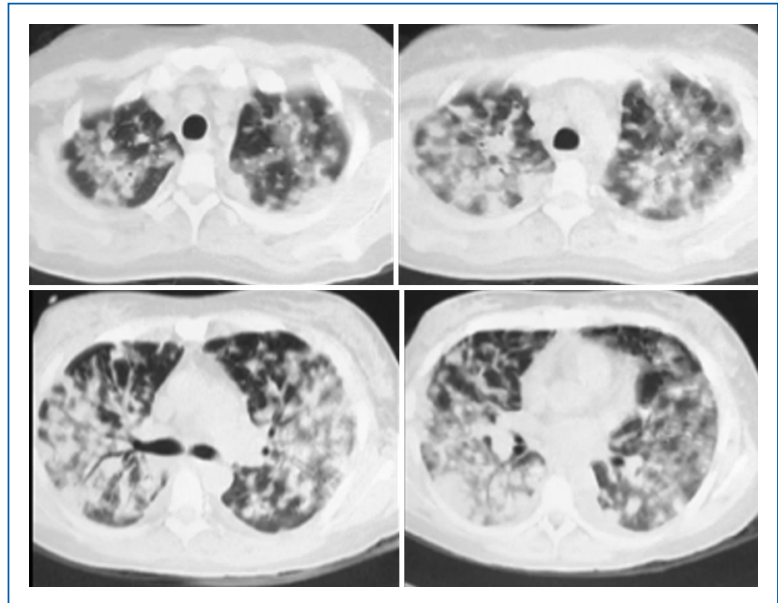

Figure 2. Chest computed tomography: "bilateral cobblestone" pattern increased bilateral pulmonary interstitial weft.

alternated with healthy parenchyma, when sectioned were granulomatous and soft; pleura of normal characteristics.

\section{Biopsy report}

Macroscopic description: irregular, grayish-brown, soft, and spongy-looking tissue fragments.

Microscopic description: prominent mononuclear inflammatory infiltrate, accompanied by multinucleated giant cells, and granuloma formation with central necrosis (Fig. 3).

Abundant oval microorganisms (1-3 microns), inside macrophages, and giant cells (Fig. 4).

Diagnosis: fragments of lung parenchyma with evidence of a severe granulomatous chronic inflammatory process, associated with the presence of microorganisms whom morphology was compatible with H. capsulatum.

Based on the histopathological result, it was decided to start treatment with Amphotericin B; however, the patient continued with progressive clinical deterioration with increased respiratory distress and the needed for advanced measures for airway management and ventilatory mechanics, later with cardiorespiratory arrest without satisfactory response to advanced support measures provided.

\section{Discussion and Conclusions}

A clinical case of a female patient with a history of renal transplantation under management of immunosuppressive

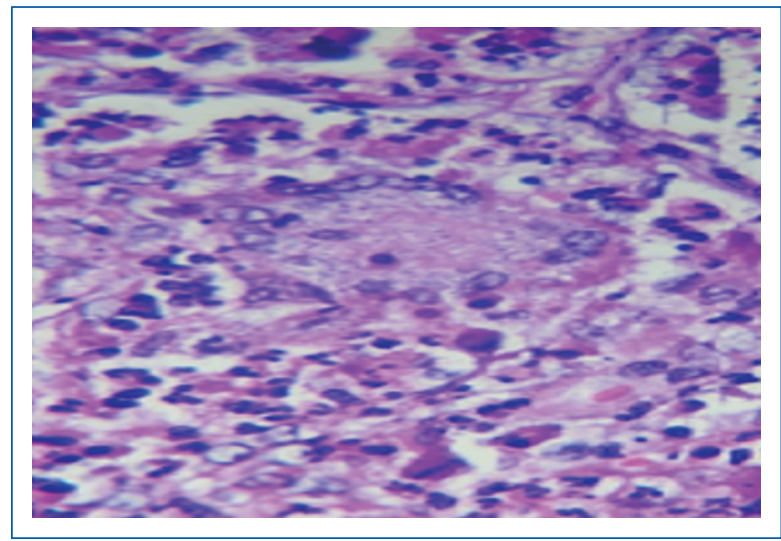

Figure 3. Microscopic view: inflammatory infiltrate, multinucleated giant cells, and granulomas.

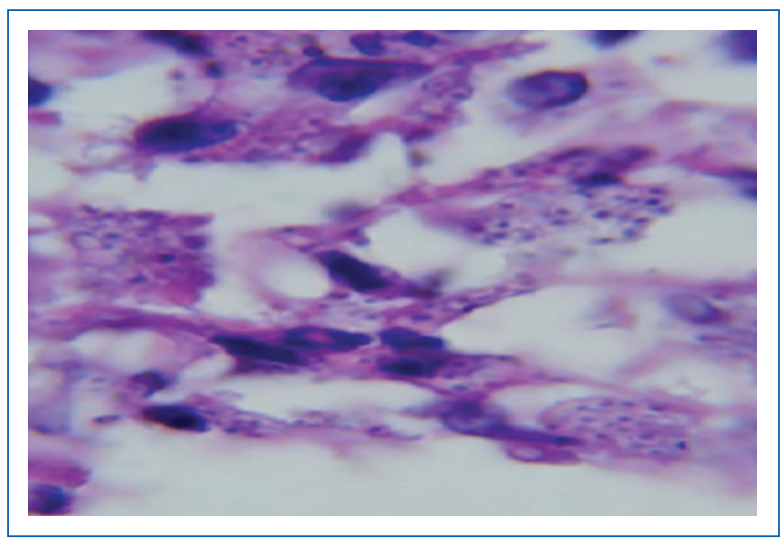

Figure 4. Intracellular microorganisms in macrophages and giant cells.

therapy with mycophenolate mofetil, tacrolimus, and prednisone is presented, who presented with atypical respiratory syndrome, it was ruled out in first instance that it presented with atypical pneumonia due to severe acute respiratory syndrome coronavirus (SARS COV)-2. Once this condition had been ruled out and based on the patient's history, other causes of atypical pneumonia were investigated, with a chest tomography report with a bilateral cobblestone pattern, given suggestive data of pathology caused by fungi. An assessment is requested by the Chest Surgery Service to perform a lung biopsy by thoracotomy; once the histopathological report, the case of severe pneumonia due to $H$. capsulatum was documented.

Risk factors to the present histoplasmosis symptoms have been associated in kidney transplant patients: renal graft dysfunction, previous acute rejection, 
immunosuppression therapy with Tacrolimus Mycophenolate, and induction with Alemtuzumab ${ }^{8}$ risk factors that the patient presented.

It has been seen that immunosuppressive therapy with the agents used by the patient (mycophenolate mofetil, tacrolimus, and prednisone), is mostly associated with severe disease and, in the case of mycophenolate, it should be suspended during active disease and, if possible, decrease the dose of calcineurin inhibitors, in this case tacrolimus and steroids prednisone being the steroid used in the patient ${ }^{9}$. For the treatment of fungal infections in patients with renal failure or with kidney transplantation, in addition to the adjustment of immunosuppressive treatment, it is essential to adjust the doses to optimize the pharmacokinetics of antifungal drugs to reduce the risk of nephrotoxicity ${ }^{10}$.

For the management of the first instance, empirical treatment was started to cover atypical agents; once confirmation of causative agent was obtained, first-line treatment with liposomal Amphotericin B was started ${ }^{11}$; however, the doses of the agents used as immunosuppressive therapy were not adjusted. Treatment regimens have been found to be highly toxic to these types of patients and are associated with significant morbidity and mortality rates.

Despite starting the therapeutic management of choice, an unfavorable response was obtained, due to the clinical severity of the onset presented by the patient, as well as the diagnostic-therapeutic delay.

The clinical presentation of the pulmonary histoplasmosis of the patient was non-specific, likewise because it presented as an atypical respiratory condition during the present contingency due to COVID-19, it was essential first to rule out SARS COV-2 as the causal agent, which complicated and delayed diagnosis of the disease, as well as timely therapy; this coupled with the patient's underlying pathology, which led to an unfavorable clinical response.

While many advances have been made in the treatment of bacterial infections, invasive fungal diseases have remained a common cause of death in immunosuppressed patients as the availability of safe and effective antifungal therapies have been limited. It has been observed that kidney transplant recipients with fungal infections have a relative risk of mortality of $2.88(95 \%$ $\mathrm{Cl}$ 2.22-3.74). The antifungal arsenal has long been insufficient and has taken a long time to diversify. In nephropathic patients, the antifungal spectrum, tolerability, and toxicity are critical issues for its management ${ }^{12}$.

Histoplasmosis and other pulmonary mycosis are rare in our community, this due to the environmental characteristics that we have; however, this and other pathologies must be taken into account due to the increase incidence and prevalence of patients in a state of immunosuppression. For this reason, the theoretical bases must be taken into consideration, as well as the implementation of the appropriate diagnosis and treatment techniques to be provided as early as possible in the event of a suspicious patient presenting.

\section{Acknowledgments}

The authors offer their sincere gratitude to the Presidente Lázaro Cárdenas General Hospital of the City of Chihuahua, as well as the nursing staff and the Department of Cardiothoracic Surgery for allowing them to obtain information about the rare case in their community to increase their knowledge about the management of this type of patients.

\section{Funding}

The authors declare that this research has not received any specific grant from agencies of the public, commercial, or non-profit sectors.

\section{Conflicts of interest}

The authors declare no conflicts of interest.

\section{Ethical disclosures}

Protection of human and animal subjects. The authors declare that no experiments were performed on humans or animals for this study.

Confidentiality of data. The authors declare that they have followed the protocols of their work center on the publication of patient data.

Right to privacy and informed consent. The authors have obtained the written informed consent of the patients or subjects mentioned in the article. The corresponding author is in possession of this document.

\section{References}

1. Bbott KC, Hypolite I, Poropatich RK, Hshieh P, Cruess D, Hawkes CA, et al. Hospitalizations for fungal infections after renal transplantation in the United States. Trans Infect Dis. 2001;3:203-11.

2. Von Lilienfeld-Toal M, Wagener J, Einsele H, Cornely OA, Kurzai O. Invasive fungal infection. Deutsches Arzteblatt Int. 2019;116:271-8.

3. Alzer H, Burchard G, Cornely OA, Lange C, Rolling T, Schmiedel S, et al. Diagnosis and management of systemic endemic mycoses causing pulmonary disease. Respir Int Rev Thoracic Dis. 2018;96:283-301.

4. Azar MM, Hage CA. Clinical perspectives in the diagnosis and management of histoplasmosis. Clin Chest Med. 2017;38:403-15. 
Rev Hosp Jua Mex. 2021;88(4)

5. Badiee $\mathrm{P}$, Alborzi A. Invasive fungal infections in renal transplant recipients. Exp Clin Transpl. 2011;9:355-62.

6. Di Mango AL, Zanetti G, Penha D, Menna Barreto M, Marchiori E. Endemic pulmonary fungal diseases in immunocompetent patients: an emphasis on thoracic imaging. Expert Rev Respir Med. 2019;13:263-77.

7. Torres P, Rabahi MF, Moreira M, Santana P, Gomes A, Marchiori E. Tomographic assessment of thoracic fungal diseases: a pattern and signs approach. Radiol Bras. 2018;51:313-21.

8. Nieto-Ríos JF, Serna-Higuita LM, Guzman-Luna CE, Ocampo-Kohn C Aristizabal-Alzate A, Ramírez I, et al. Histoplasmosis in renal transplan patients in an endemic area at a reference hospital in Medellin, Colombia. Transpl Proc. 2014;46:3004-9.
9. Gajurel K, Dhakal R, Deresinski S. Diagnosis and treatment of histoplasmosis in solid organ transplant patients. Curr Opin Infect Dis. 2018;31:301-8.

10. Haydour Q, Hage CA, Carmona EM, Epelbaum O, Evans SE, Gabe LM, et al. Diagnosis of fungal infections. A systematic review and meta-analysis supporting American thoracic society practice guideline. Ann Am Thorac Soc. 2019;16:1179-88.

11. Azar MM, Loyd JL, Relich RF, Wheat LJ, Hage CA. Current concepts in the epidemiology, diagnosis, and management of histoplasmosis syndromes. Sem Respir Crit Care Med. 2020;41:13-30.

12. Nivoix $Y$, Ledoux MP, Herbrecht, R. Antifungal therapy: new and evolving therapies. Sem Respir Crit Care Med 2020;41:158-74. 